\title{
Optimizing Lumber Production through Improved Accuracy of Side Clearance of Bandsaw Teeth and Quality Control Measures
}

\author{
Mitchual, S. J. \\ Department of Technology Education, University of Education, Winneba \\ Okai, R. \\ Department of Technology Education' University of Education, Winneba \\ Frimpong-Mensah, $\mathbf{K}$. \\ Department of Wood Science and Technology, Faculty of Renewable Natural Resources, \\ Kwame Nkrumah University of Science and Technology, Kumasi, Ghana.
}

\begin{abstract}
As log costs increases as a result of increasing demand for wood products with a corresponding poor management of forest resource it has become more critical to obtain the maximum yield of useful product from each tree in order to sustain the wood industry. This work looks at the effect of the accuracy of side clearance of band saw teeth on the surface quality of sawn lumber as well as the level of adherence to quality standards when sawing Triplochiton scleroxylon (Wawa). The results obtained from the relationship between the accuracy of side clearance of band saw teeth and surface quality of sawn lumber indicates that there is a strong linear relationship between the two parameters. That is as the standard deviation of the side clearance of the band saw teeth decreases the surface quality of the sawn lumber becomes better. The correlation coefficient and coefficient of determination values for the two variables, that is, the accuracy of side clearance of the band saw teeth and the surface quality of the sawn lumber were -0.9042 and 0.8176 respectively. These values show that about $82 \%$ of the variations of the surface quality of the sawn lumber is influenced by the standard deviation of the side clearance of the band saw teeth. A graph of the relationship between the surface quality of the sawn lumber and standard deviation shows that on the average when the standard deviation of the side clearance of the band saw teeth is $0.225 \mathrm{~mm}$ or low the surface quality of the sawn lumber produced could be qualitatively classified as good, very good or excellent. The result also indicated that the surface quality of the sawn lumber was excellent when the standard deviation of the side clearance of the band saw teeth was $0.07 \mathrm{~mm}$ or low and was poor or very poor when the standard deviation of the side clearance was $0.252 \mathrm{~mm}$ or more. A statistical control chart of sampled boards from the production process of the mill used for the study indicated that the mean thickness of the sawn boards was $42.42 \mathrm{~mm}$. The upper and lower control limits at 1.65 standard deviation were $44.08 \mathrm{~mm}$ and $40.76 \mathrm{~mm}$ respectively. The result indicates that about $15 \%$ of the total boards sampled were outside the control limits of the chart. The mean thickness of the sawn lumber at the mill for the study was $42.42 \mathrm{~mm}$ as against nominal thickness of $41.00 \mathrm{~mm}$. This will result in a loss of about $3.46 \%$ timber for every board sawn and a subsequent loss of about $3.46 \mathrm{~m}^{3}$ for every $100 \mathrm{~m}^{3}$ of sawn lumber produced.
\end{abstract}

Keywords side clearance, band saw teeth, standard deviation, statistical control chart

\section{Introduction}

The secret of successful wood machining is the interplay between man, machine, tool and money (Uddeholm strip steel AB, 1989). Throughout the wood industry in the world, there is a strong desire for the most effective utilization of logs in order to reduce pressure on the forest. Expansion in the industry these days depends on reducing waste, using more of every log and generally putting in place some quality control measures to increase the yield.

The management of a sawmill in the United State of America made a concerted effort to reduce sawing variation, excess tolerance on targeted sizes and to improve sawing practices through the use of pragmatic quality control process all in collaboration with the sawmill improvement program (SIP). As a result, raw material requirement was reduced by $12 \%$, which was equivalent to a $\log$ input savings of $\$ 1.2$ million (Bindley, 1982). Tooth marks and sawing variation adversely affect lumber yield in that excessive planing is required in order to produce acceptable finished good grade boards. In situations were the lumber is not planed before selling, such defect result in the down grading of the lumber hence resulting in price reduction. A deviation in target size of lumber is also 
a cost solely to the producer. Other cost associated with poor quality of lumber produced could be the lost of goodwill as well as rejection of consignment by the buyers.

The main saw conditions that influence sawing accuracy include faulty condition of saw, such as the technique of setting and sharpening of teeth (Telford, 1958, Murata et al, 1993). Uneven filling result in uneven sharpness of the saw teeth. At the same time, it produces unequal side clearance for the individual teeth, which leads to the production of lumber with poor surface quality as well as dimensional inaccuracies. Crosby (1985) defined quality as the conformance to requirements. In the context of lumber, Brown (1982) defined quality in the broad sense as caring through the manufacturing process and providing quality assurance in the finished product. In this work the quality characteristic that are of interest are the quality of the sawn lumber and the level of adherence to quality standards when processing lumber at the sawmills.

\section{Materials and methods}

A $1328 \mathrm{~mm}$ band mill with auto feed carriage and rated motor power of $110 \mathrm{hp}$ and spindle speed of 1440 revolutions per minute (rpm) was used for the study. Four bandsaw blades with similar dimensions and specifications were randomly selected from a total of ten bandsaw blades. The specifications of the saws are as follows: blade width; $152 \mathrm{~mm}$, blade thickness; $1.3 \mathrm{~mm}$, number of teeth; 209, tooth pitch; $45 \mathrm{~mm}$, tooth height; $16 \mathrm{~mm}$, and rake angle; 27 degrees. Each of the four saws was stellite-tipped. The stellite tipping was done by depositing a stellite material which is composed of $58 \%$ cobalt, $29 \%$ chromium and $9 \%$ tungsten on the teeth of the saws by the conventional method, that is, the rod of the stellite which is $3.2 \mathrm{~mm}$ in diameter was melted with an oxyacetylene flame and their melted pieces were manually welded unto the rake faces of the swage teeth. The four stellite- tipped saws were then sharpened and side dressed with grinding wheels. The inner and outer side clearances of the stellite- tipped saws Xi and Xo respectively shown in Figure 1 were measured with a side gauge or dial indicator as shown in Figure 2.
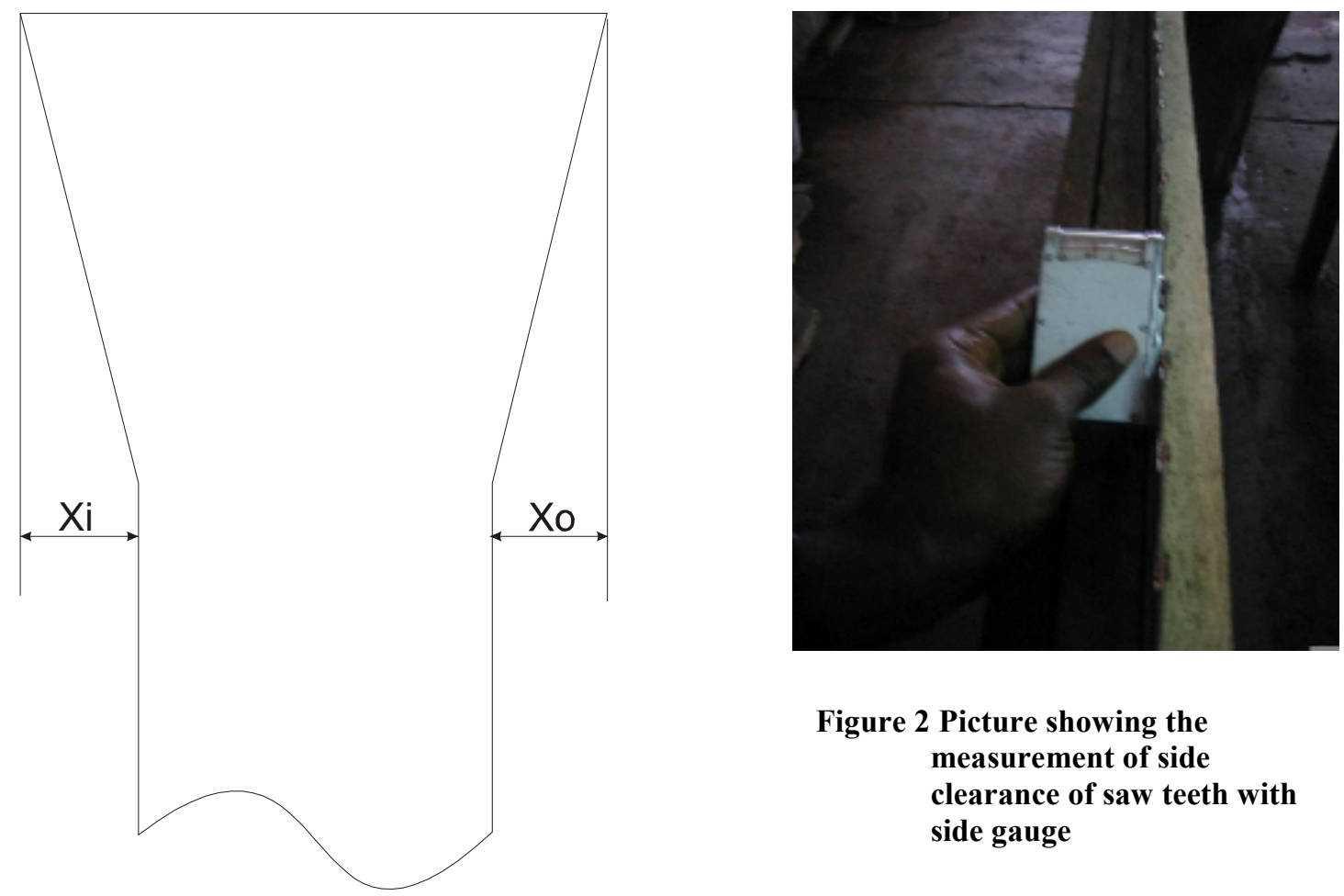

Figure 2 Picture showing the measurement of side clearance of saw teeth with side gauge

Figure 1 Sketch of a band saw tooth showing the inner side clearance $X_{i}$ and outer side clearance $X_{0}$

I ne accuracy or the side crearance or tne banasaw teeth was computed as the standard deviation of the side clearance of the saw teeth. Mathematically the standard deviation of the side clearance for the 209 teeth can be calculated as; 


$$
\begin{aligned}
& \text { Standard Deviation }=\sqrt{\frac{\sum_{x=1}^{n} x^{2}-\left(\left(\sum_{x=1}^{n} x\right)^{2} / n\right)}{n},} \\
& \text { where } \begin{aligned}
x & =\text { Side clearance of band saw teeth, and } \\
n & =\text { Total number of teeth. }
\end{aligned}
\end{aligned}
$$

The saws were used to rip-saw green beams of Triplochiton scleroxylon (Wawa) of average moisture content $63.6 \%$ into lumber of nominal thickness $41 \mathrm{~mm}$ at an average feed speed of $13.22 \mathrm{~m} / \mathrm{min}$ and depth of cut $420 \mathrm{~mm}$. The average feed speed was determined by measuring the length of the beam with a steel tape and the average time required to saw a board was recorded with a stop clock. Ten boards were randomly selected after each saw was used to saw a beam into lumber. The surface quality of the sampled boards were qualitatively graded into 1,2,3,4,5 which corresponds to surface quality: very poor, poor, good, very good, and excellent respectively using surfaces a ,b ,c ,d and e as shown in Figure 3.
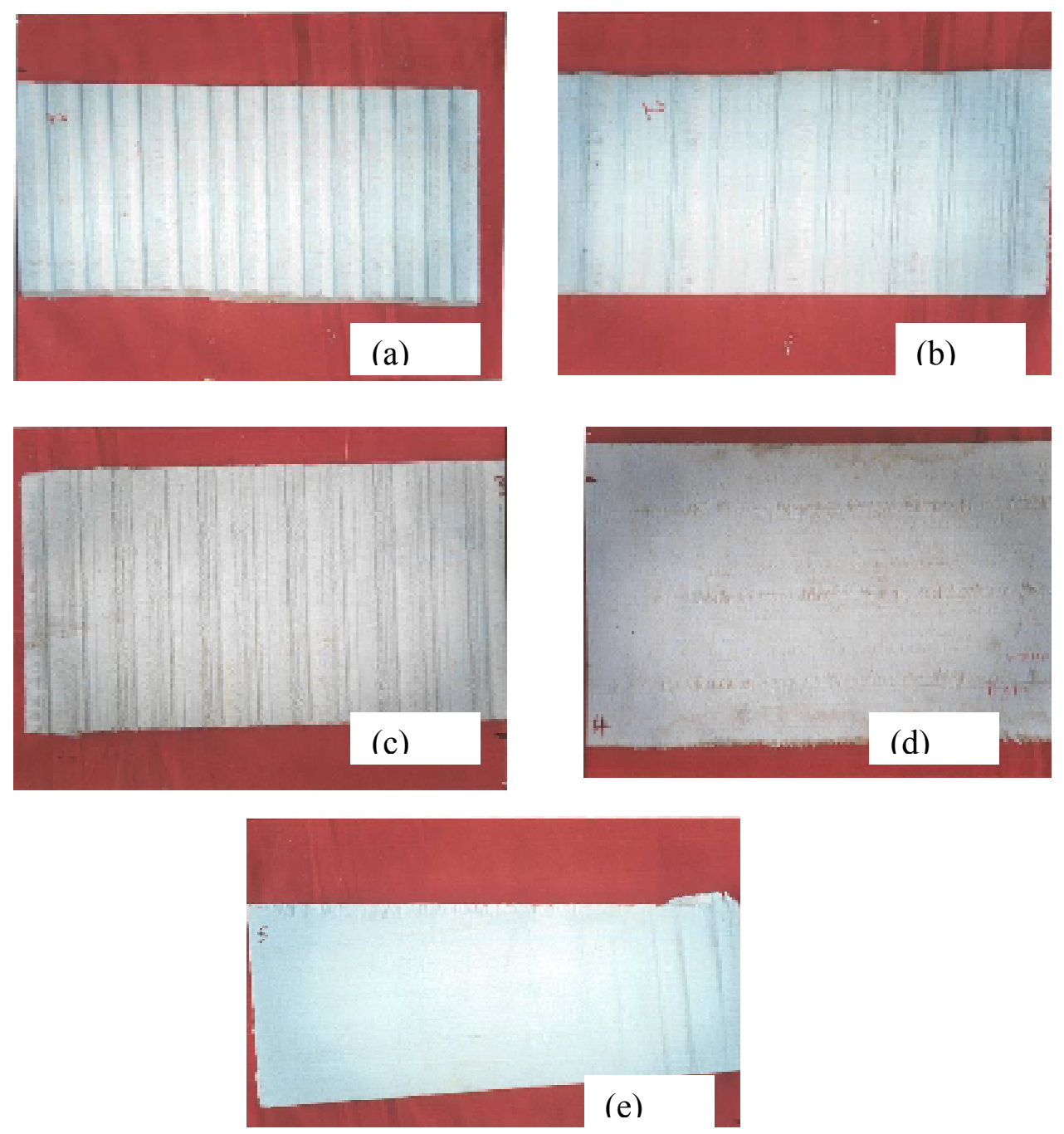

Figure 3 Surface quality of the sampled boards graded qualitatively into surface quality: Very Poor, Poor, Good, Very Good, and Excellent, respectively using surfaces a, b, c, d \& e 
The experiment was repeated anytime the saws were sharpened. Six boards were also sampled from each pallet of sawn boards during the production process. Their thickness was measured at ten locations on the board using vernier calipers. This was to find out if the entire production process was within acceptable levels of quality standard. In all forty sampling was done.

\section{Results and discussion}

\section{Relationship between accuracy of side clearance of stellite-tipped saws and surface quality of sawn lumber}

Uneven setting as well as uneven filling produces unequal side clearance for the individual teeth of band saw blade. This then results in the production of lumber with poor surface quality as well as dimensional inaccuracy (FAO, 1985). The result of the study for the relationship between the accuracy of the side clearance and surface quality of sawn lumber for the four saws used are as presented in Figure 4.
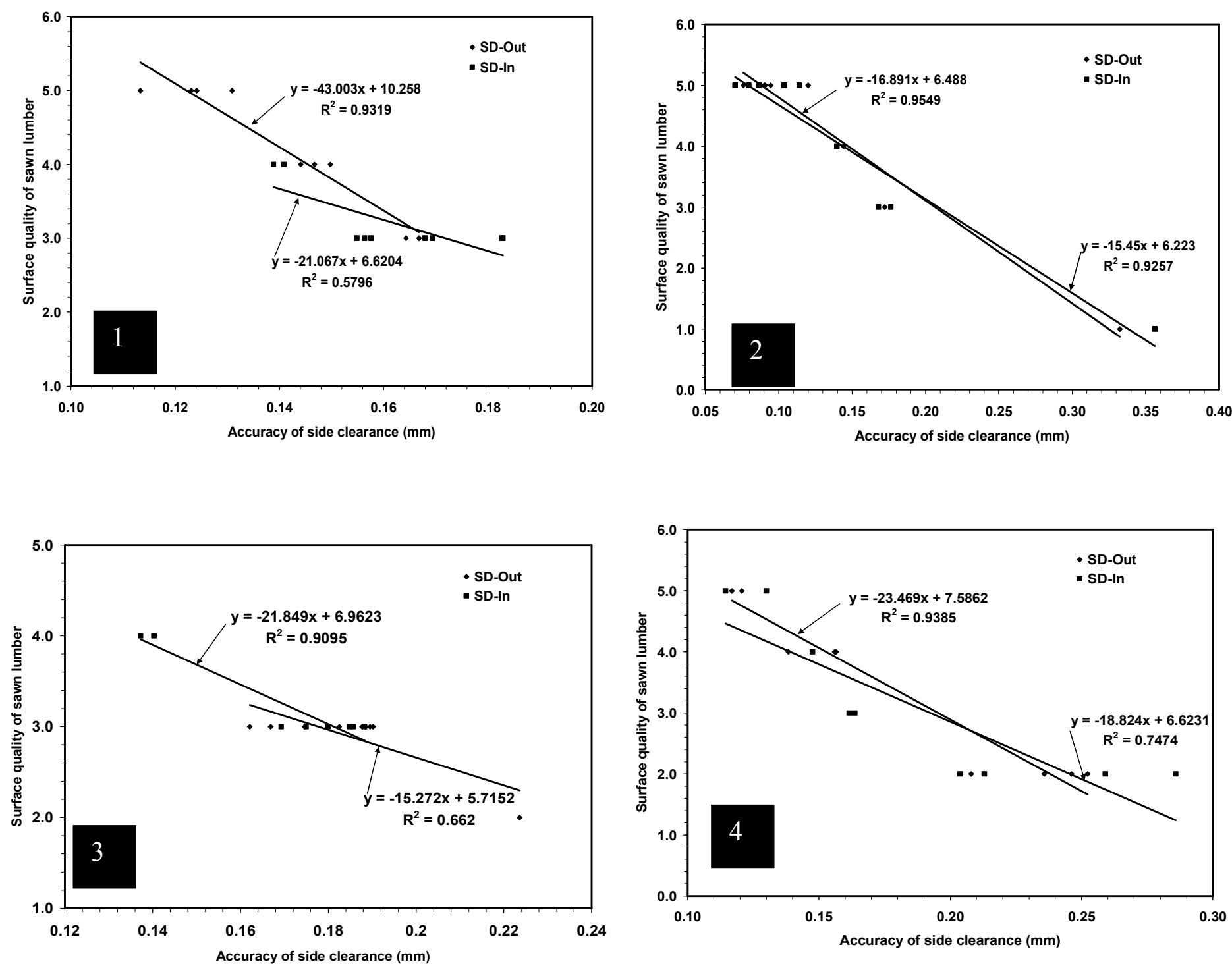

Figure 4 Graphs of relationship between accuracy of side clearance and surface quality of sawn lumber when four different saws used to saw beams of Triplochiton scleroxylon (1, 2, 3 and 4 shows the relationship between accuracy of side clearance and surface quality) 
SD - Out

SD - In

These represent a graph of standard deviation of outer side clearance of the band saw teeth against surface quality of sawn lumber.

These represent a graph of standard deviation of inner side clearance of the band saw teeth against surface quality of sawn lumber.

The result generally indicates that higher values of standard deviation of side clearance produce poorer surface quality of sawn lumber. Extracts from Figure 4 is as shown in Table1. The correlation coefficient values for SD-out and SD-in for all the four saws shown in Table 1 ranges from -0.7613 to -0.9772 with majority of them being greater than -0.9 . This is an indication of a strong linear relationship between surface quality of sawn lumber and the standard deviation of the side clearance of the saws used. That is, as the standard deviation of the side clearance increases the surface quality of sawn lumber becomes poorer. Again extracts from the graph in Figure 4 which is presented in table 1 shows that the coefficient of determination values which indicate the extent to which the surface quality of the sawn lumber depends on the standard deviation of the side clearance of the saws ranges from 0.5796 to 0.9549 . This values when expressed in percentages range from $58 \%$ to $96 \%$.

Table 1 Extract from the graph of the relationship between accuracy of side clearance of band saw teeth and surface quality of sawn lumber

\begin{tabular}{|c|c|c|c|c|c|c|}
\hline \multirow[b]{2}{*}{$\begin{array}{c}\text { Saw } \\
\text { no. }\end{array}$} & \multicolumn{2}{|c|}{ Equations of graphs } & \multicolumn{2}{|c|}{$\begin{array}{l}\text { Coefficient of } \\
\text { determination } \\
\left(\mathrm{R}^{2}\right)\end{array}$} & \multicolumn{2}{|c|}{$\begin{array}{l}\text { Correlation } \\
\text { coefficient } \\
(\mathrm{R})\end{array}$} \\
\hline & SD-Out & SD-In & SD-Out & SD-In & SD-Out & SD-In \\
\hline 1 & $S_{q}=-43.003 x+10.258$ & $S_{q}=-21.067 x+6.6204$ & 0.9319 & 0.5796 & -0.9654 & -0.7613 \\
\hline 2 & $\mathrm{~S}_{\mathrm{q}}=-16.891 \mathrm{x}+6.488$ & $\mathrm{~S}_{\mathrm{q}}=-15.45 \mathrm{x}+6.223$ & 0.9549 & 0.9257 & -0.9772 & -0.9621 \\
\hline 3 & $\mathrm{~S}_{\mathrm{q}}=-15.272 \mathrm{x}+5.7152$ & $\mathrm{~S}_{\mathrm{q}}=-21.849 \mathrm{x}+6.9623$ & 0.6620 & 0.9095 & -0.8136 & -0.9537 \\
\hline 4 & $S_{q}=-23.469 x+7.5862$ & $\mathrm{~S}_{\mathrm{q}}=-18.824 \mathrm{x}+6.6231$ & 0.9385 & 0.7474 & -0.9688 & -0.8645 \\
\hline
\end{tabular}

The result in Table 2 shows the combined effect of the relationship between accuracy of side clearance of stellite-tipped saws and surface quality of the sawn lumber for all the four saws used. It shows that as the standard deviation of the side clearance decreases the surface quality of the sawn lumber becomes better.

\begin{tabular}{|c|c|c|c|c|c|}
\hline \multicolumn{2}{|c|}{ Table 2} & \multicolumn{4}{|c|}{$\begin{array}{l}\text { Surface quality of sawn lumber and mean accuracy of side clearance of a } \\
\text { four saws }\end{array}$} \\
\hline$e$ & \multicolumn{4}{|c|}{ Mean standard deviation of side clearance (mm) } & \multirow[b]{2}{*}{ All the four saws } \\
\hline quality & Saw - 1 & Saw - 2 & Saw -3 & Saw - 4 & \\
\hline 1 & - & 0.3443 & - & - & 0.3443 \\
\hline 2 & 0.1441 & - & 0.2066 & 0.2380 & 0.1962 \\
\hline 3 & 0.1670 & 0.1723 & 0.1797 & 0.1473 & 0.1666 \\
\hline 4 & 0.1441 & 0.1420 & 0.1512 & 0.1497 & 0.1468 \\
\hline 5 & 0.1229 & 0.0921 & - & 0.1217 & 0.1122 \\
\hline
\end{tabular}

A graph of the combined effect of the relationship between surface quality of sawn lumber and the standard deviation of all the four stellite-tipped saws used for the study indicated in Figure 5 shows that on the average when the standard deviation of the side clearance is $0.225 \mathrm{~mm}$ or low the surface quality of the sawn lumber produced by the four saws could be qualitatively graded as either good, very good or excellent. The graph also indicates that the surface quality of the sawn lumber was excellent when the standard deviation of the side clearance was $0.07 \mathrm{~mm}$ or low and was poor or very poor when the standard deviation of the side clearance was $0.252 \mathrm{~mm}$ or more. Also the coefficient of determination value for all the four saws combined is 0.8176 which indicate that about $82 \%$ of the surface quality of the sawn lumber depends on the standard deviation of the side clearance of the saws.

Although surface quality of sawn lumber is also influenced by other factors such as the rake angle and the pitch size of the saw blade as indicated by Wood news (1993) that large pitch i.e. lower number of teeth per $2.54 \mathrm{~m}(1 \mathrm{inch})$ will allow high speeds but will give a poorer surface and uddeholm strip steel AB (1991) that small amount of hook angle gives a smoother surface of sawn lumber than a large one, these two parameters were adequately selected to play down their effect 
on the surface of the sawn surface. Hence the major factor that influenced the surface quality of the sawn boards was the standard deviation of the saw teeth.

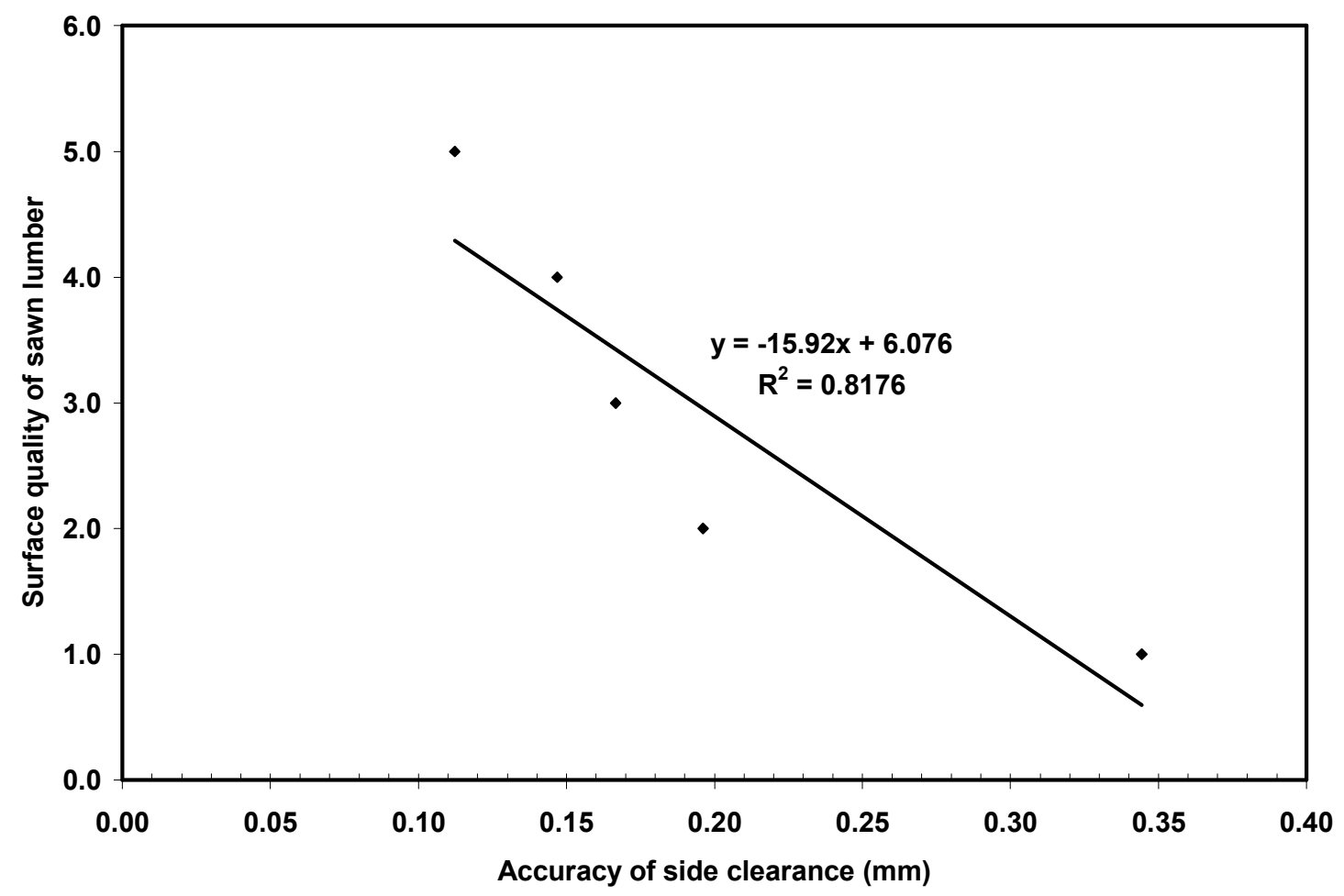

Figure 5 Relationship between surface quality of sawn lumber and mean standard deviation of side clearance of band saw teeth for all the four stellite-tipped saws.

\section{Quality control}

The objective of a statistical process control of quality is to achieve a process that is stable, predictable and capable to deliver products that meet the requirements of the customers almost all the time. The statistical process control chart of the boards sampled from the production stream is as indicated in Figure 6.

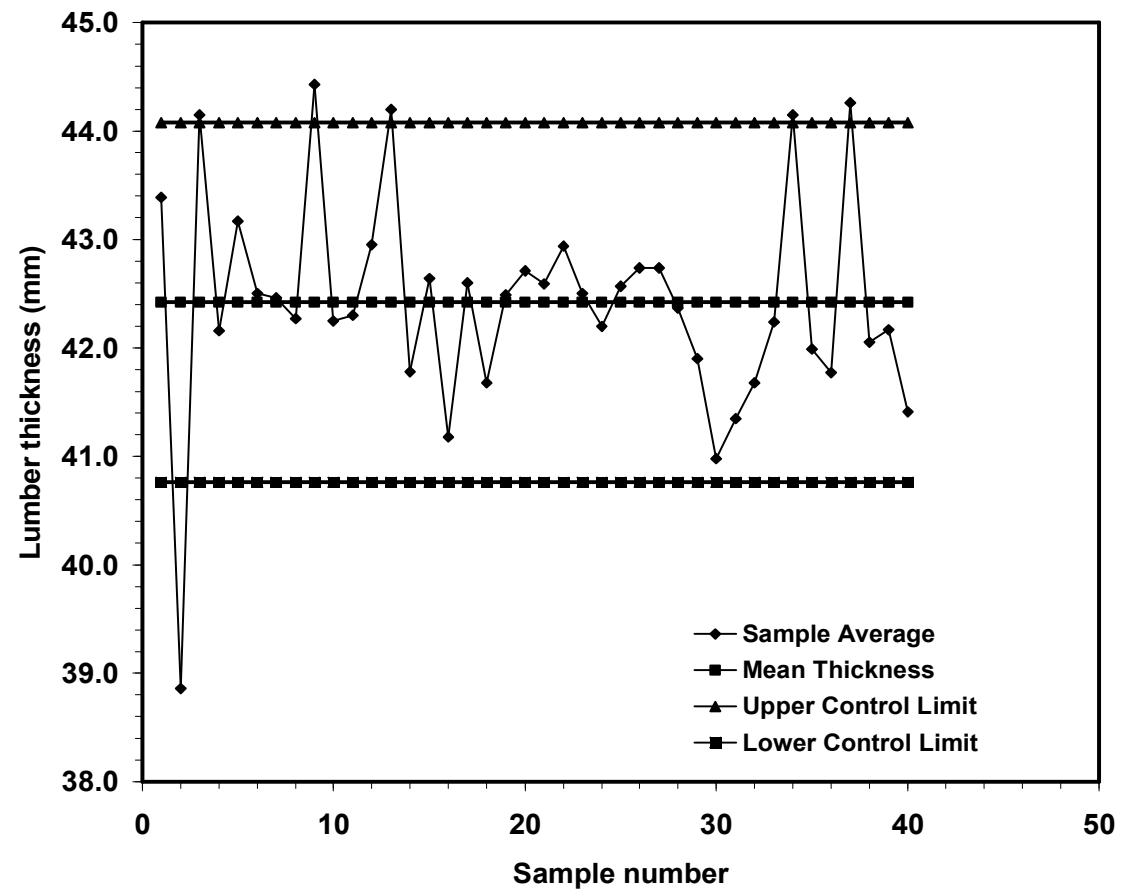

Figure 6 Statistical process control chart for thickness of 40 samples of sawn lumber 
The result indicates that the mean thickness of the sawn boards sampled was $42.42 \mathrm{~mm}$. The upper control limit (UCL) at 1.65 standard deviation was $44.08 \mathrm{~mm}$ and the lower control limit (LCL) at 1.65 standard deviation was $40.76 \mathrm{~mm}$. The result also shows that about $15 \%$ of the total boards sampled from the production stream were outside the control limits of the chart. This is a strong indication of sporadic variation in the production process, which indicates that the production process was out of control. According to Sagoe and Hellem (1998), 10\% of the total consignment of lumber for export is often the allowance that can be accepted to be defective in size. Anything greater than this could attract export claim which could be a great cost to the company. The result in Figure 6 also shows that the mean thickness of the sawn lumber which was $42.42 \mathrm{~mm}$ was greater than the nominal thickness or targeted thickness of the sawn boards which is $41.00 \mathrm{~mm}$ by $1.42 \mathrm{~mm}$. This will lead to a loss of about $3.46 \%$ of timber for every board sawn and a subsequent loss of about $3.46 \mathrm{~m}^{3}$ for every $100 \mathrm{~m}^{3}$ of sawn lumber produced.

\section{Conclusion}

This paper examined the effect of accuracy of side clearance of stellite-tipped band saw blades on the surface quality of sawn lumber when processing Triplochiton Scleroxylon (Wawa). It also looked at the extent to which quality control measures can affect production output. The results of the study are as follows: The work established a strong negative linear relationship between accuracy of side clearance and surface quality of sawn lumber $(\mathrm{R}=-0.9042)$. The results also indicated that about $82 \%$ of the surface quality of the sawn lumber depended upon the standard deviation of the side clearance of the band saw blades. Surface quality of sawn lumber was good, very good or excellent when the standard deviation of the side clearance was $0.225 \mathrm{~mm}$ or low. Statistical control chart of sampled boards from the production process of the mill used for the study indicated that $3.46 \mathrm{~m}^{3}$ of wood fiber was lost for every $100 \mathrm{~m}^{3}$ of lumber produced as a result of excessive tolerance on sawn lumber.

\section{References}

Brindley R. \{1992). The sawmill improvement programme. An opportunity for improved recovery. Proceedings of manufacturing lumber from small logs. University of Washington 44: PP4748.

Brown T D. (1982). Quality control in lumber manufacturing. Franciscos: Miller Freeman Publication Inc. PP 12-25.

Crosby P B. (1985). Quality without tears. The Art of Hassle-Free Management. N.Y: McGraw-Hill PP 5-60.

Murata K et al. (1993). Sawing performance of bandsaws treated with new filling methods 1 . Journal of the Japan wood research society. 39(11) PP 1231-1238.

Sagoe J A. and S. Hellem. (1998). Tolerance on green lumber dimension for selected tropical timber of Ghana, TEDB report, Ghana PP 2-10.

Uddeholm strip steel AB. (1991). Wood bandsaw blade manual, $2^{\text {nd }}$ edition. Munkfors Sweden: Uddeholm Strip Steel A.B.. PP 5-40.

Wood News (1993). Bandsaw blades: Criteria for selection and use. Wood News vol.2 (4) PP 44-53. 